\title{
Agile Adoption in IT Organizations
}

\author{
Imran Ghani ${ }^{1}$, Mannir Bello ${ }^{1}$ \\ ${ }^{1}$ Department of Software Engineering, Faculty of Computing, Universiti Teknologi Malaysia, Skudai, 81310, \\ Johor, Malaysia \\ [e-mail: imran@utm.my] \\ *Corresponding author: Imran Ghani
}

Received April 1, 2015; revised June 8, 2015; accepted June 13, 2015;

published August 31, 2015

\begin{abstract}
Many IT organizations aspire to improve the efficiency and general standard of their software development effort by implementing agile software development practices. Some of the popular agile development methods adopted by IT organizations are Scrum, eXtreme Programming (XP), Kanban, Featured Driven Development (FDD) and Dynamic System Development Method (DSDM). This paper intends to identify and analyze the barriers that impact on the performance of IT organizations that use such agile software development methods. The analysis will help the IT organizations to cater the needed aspects to be successful. The analysis will also help the IT organizations to select the right methodology for their organization. The contribution of this analysis is to present guideline related to avoid or overcome the barriers towards adoption of agile.
\end{abstract}

Keywords: Agile Adoption, Scrum, eXtreme Programming, DSDM, FDD, Kanban,

\footnotetext{
A preliminary version of this paper was presented at ICONI 2014, and was selected as an outstanding paper.
} 


\section{Introduction}

In today's dynamic age, businesses change rapidly to meet with the competition, hence requirements tend to change respectively for the software projects. In such scenarios, agile software development methods have emerged as an alternative to traditional plan driven software development methods more than a decade ago [3]. Nowadays they are often considered as the mainstream in software engineering. This is often explained with their potential to overcome the challenges of modern software organizations which are expected to operate in highly dynamic and competitive environments. In such environments speed of software delivery, quality of software and cost of software development are crucial for organizational development and survival. In this context, agile approach seems to be successfully delivering on all these three fronts through their customer focus, responsiveness to change, iterative and incremental delivery of working software and emphasis on individuals and their interactions [1-2].

\subsection{Problem background and motivation}

As mentioned in the above paragraph that traditional methodologies such as waterfall method, or spiral method cannot handle the increasing problems faced by modern IT organizations such as fast deliverance of software to market, generate more revenue, learning new skills and recurrent changes that are needed at the time of development and maintenance cycle [4]. With the adoption of agile development methodologies such as Scrum [7-8-9], XP [10-11-12-25], FDD [13-14-15], DSDM [6] and Kanban [16] proponents argue that they are able to tackle these problems properly. Due to the importance of this phenomoenon, this research was initiated to validate that whether, after adpoting agile methods, a significant impact on the performance of organizations was achieved or not[5-6-18-19-20]. The findings of this study also present the barriers that resist practitioners to promote agile methods in their organisations.

\subsection{Barriers to Further Agile Adoption in Organisations 2008 and 2014}

Based on Rico [22] shown in Fig. 1 (survey conducted in 2008 is shown in left figure) and our own survey conducted in LinkedIn in 2014, Fig. 2 (shown in right figure). In this study, we identified barriers to agile adoption. In 2008, as shown in Fig. 1 (left), the changing of organizations culture (resistance to change) was the number one barrier to further adoption. In 2014, as shown in Fig. 1 (right), the lack of experience in agile methodologies among the software teams was the first and foremost barrier to further agile adoption. This was followed by the ability to manage changes and to fit agile elements in to non-agile framework (Co-located agile teams). 

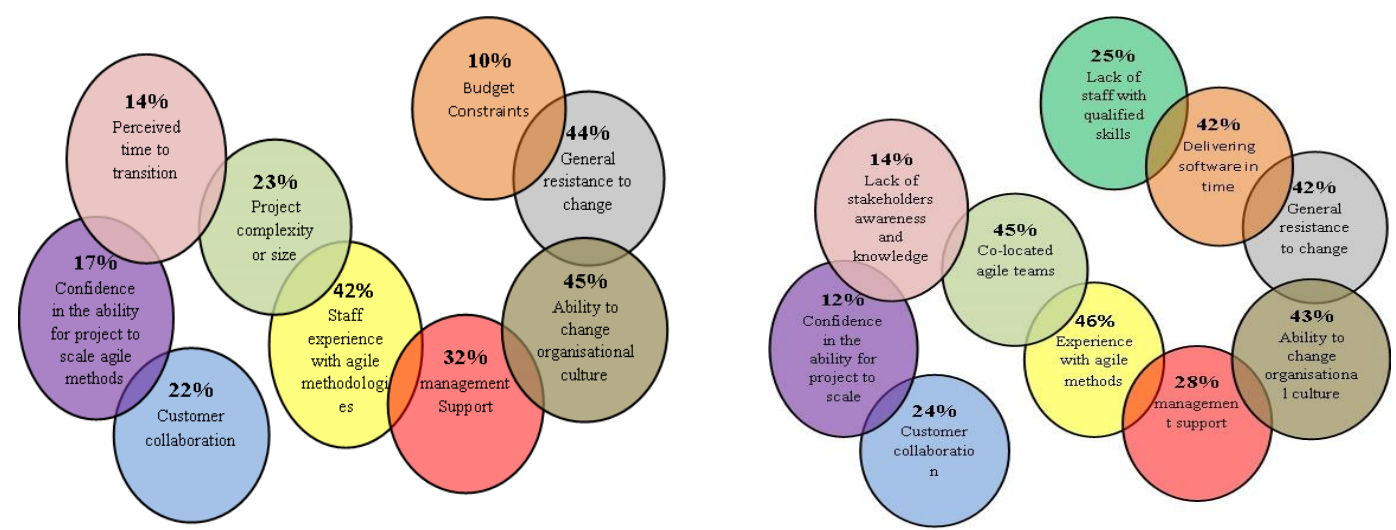

Fig. 1. Barriers to further agile adoption in organizations in 2008 and 2014

\section{Research Analysis}

Toward making reasonable development in this area we have created a survey questionnaire online and conduct an online web survey via Linkedin. We distributed survey link to 420 agile practitioners across the world. There were 34 questions asked that reflect success factors considers in adoption and implementation of agile software development methods. Some of the example questions asked in the survey are as follows;

1. Professional position in the organization?

2. Employees/work force size of development team?

3. Experience in agile software development of team members and the organization?

4. Most successful agile method in projects?

5. Number of agile projects in organization?

6. Involvement of co-located agile teams?

7. Success rate of co-located agile teams?

8. ROI increased after agile adoption in organization?

9. Effects of agile practices on satisfaction of stakeholders (customers, developers)?

10. Agile method preferably adopted by your organization?

Based on various surveys (Fig. 1) there are different factors and findings in delivering the benefits of agile software development methods to organizations and companies depend on the type of research survey conducted. From this analysis we can figure out that these factors have impacted positively in agile software development methods as a result organisations will great achievements interms of return of investment, reduce cost, increase efficiency and improve customers satisfaction in general. 


\subsection{Summary of Barriers to Further Agile Adoption in Organisations 2008, 2013 and 2014.}

In Fig. 2, we can see that the ability to change the culture of organizations was the number one barrier to adoption of agile in 2008. While in 2014, confidence and experience in using agile methods was the main barrier. The reason of the lack of confidence in using agile methods could be linked to the hot discussion on "what agile is not?" In 2014, we noticed that on almost every forum (meet ups, symposiums or conferences etc) a number speakers were presenting contradicting concepts on agile. One speakers used to say "this is what agile means!" another speaker used to contradict that concept and said "No, that is not agile", rather "agile means this, this and that". For instance, a speaker in a talk said "Agile is nothing without Test Deiven Development (TDD)". In an other occeason, an other speaker said TDD is not part of Agile, rather "agile is a mind-set".

These face-to-face or online discussions created confusion among the software teams and led them to less confidence; as they were not clear whether what they were doing was agile or not! Even the definition of "Done" got enormous arguments.

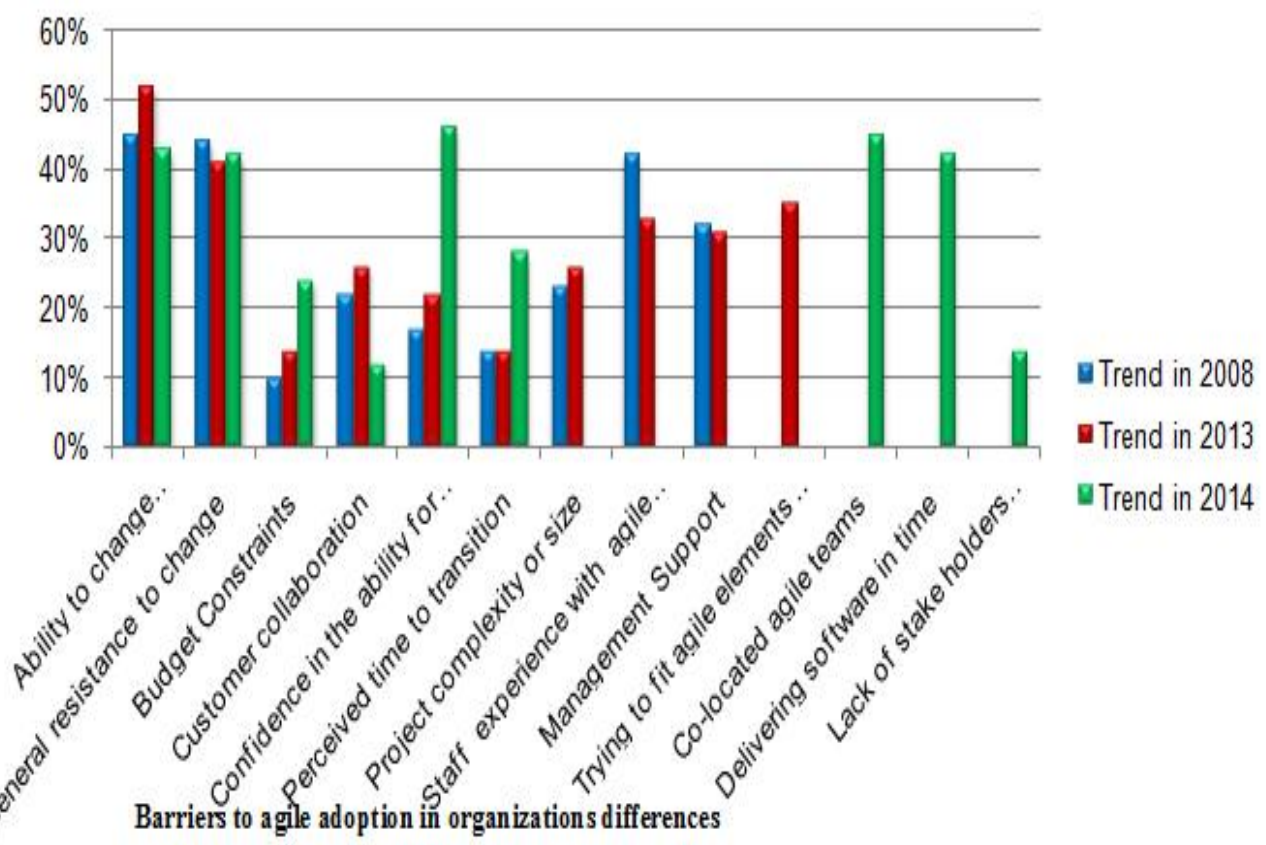

Fig. 2. Barriers to further agile adoption in organizations, 2008, 2013 and 2014.

Followed by the general resistance to change and trying to fit agile elements into a non-agile structure and lack of experience in agile methodologies, perceived time to agile transition and budget constraint had the lowest impact on agile adoption in 2014. 
Similarly, in 2013, the changing of organizations culture was the number one barrier to agile adoption. Followed by general resistance to change and trying to fit agile elements into a non-agile structure. Perceived time to transition and budget constraints had the lowest impact on further adoption.

\section{Results}

The result of our survey is based on 103 respondents out of 420 invitation sent to several agile practitioners across the globe usig Linkedin. Though the response ration is low (25\%) and may not present a broad picture of large population yet it could still help us to draw conclusion for the succesful adoption and inplementation of agile methods in the organizations of 103 respondents.

\subsection{Popular adopted agile methodology}

As shown in Fig. 3 below, we can vividly deduce that Scrum is the most popular agile methodology adopted by practitioners with $55.66 \%$. Next Scrum is extreme programming with $13.20 \%$ and Kanban with $8.49 \%$.

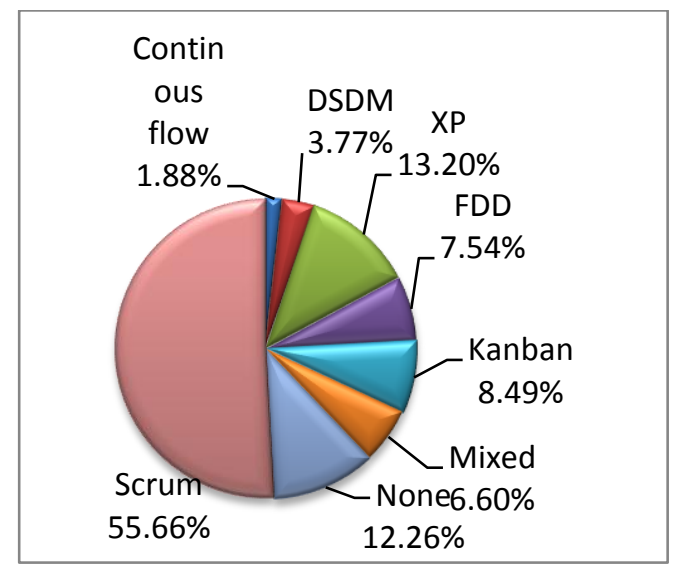

Fig. 3. Popular adopted agile methodology $(\mathrm{N}=103)$.

\subsection{Agile approches increase managers satisfaction}

Most of the respondents within the range of 50\% to $90 \%$ (Fig. 4) said that agile approaches increased managers satisfaction significantly. At the same time those within the range of $90 \%$ to $100 \%$ saaid agile approaches have increased managers satisfaction. 


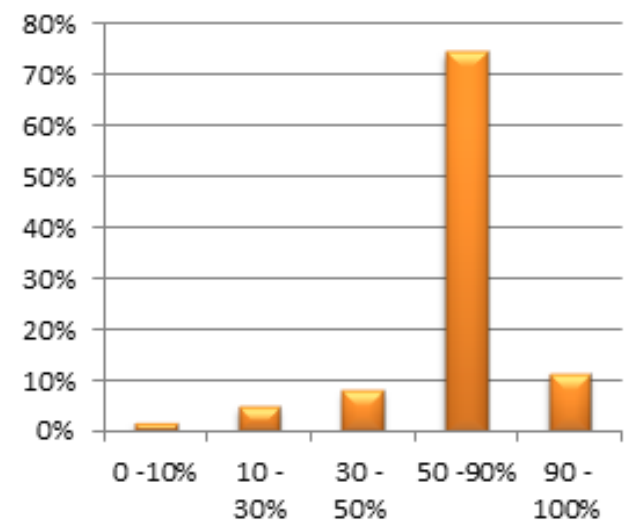

Fig. 4. Agile approaches increase managers satisfaction $(\mathrm{N}=103)$.

\subsection{Agile approches increase developers satisfaction}

Most of the respondent within the range $50 \%$ to $90 \%$ (Fig. 5) said that agile approaches increased developers satisfaction reasonably. Moreover, those within the range of $30 \%$ to $50 \%$ and $90 \%$ to $100 \%$ have recognized agile approaches have increased developers satisfaction positively, however $0 \%$ to $10 \%$ say they don't know.

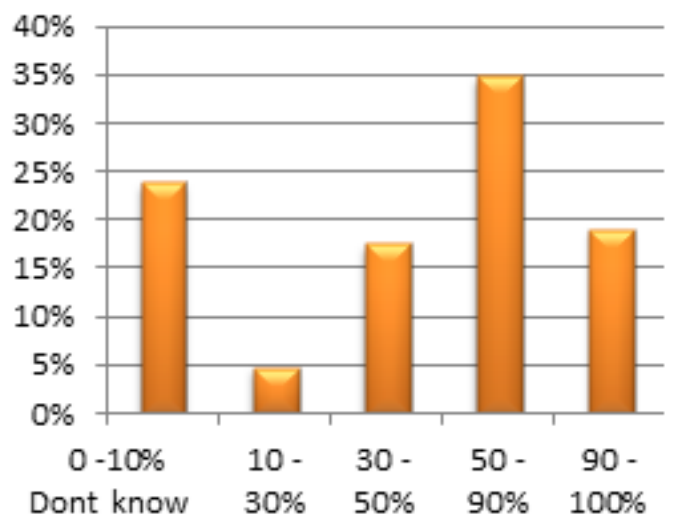

Fig. 5. Agile approaches increase developers satisfaction ( $\mathrm{N}=103)$.

\subsection{Agile approches increase customers satisfaction}

Most of the respondent within the range of $50 \%$ to $90 \%$ (Fig. 6) said that they witnessed agile approaches increased customers satisfaction and those within the range of $30 \%$ to $50 \%$ 
said agile approaches increased customers satisfaction. However, it is imperative to note that all the remaining ranges testified that there was increase in satisfaction of customers.

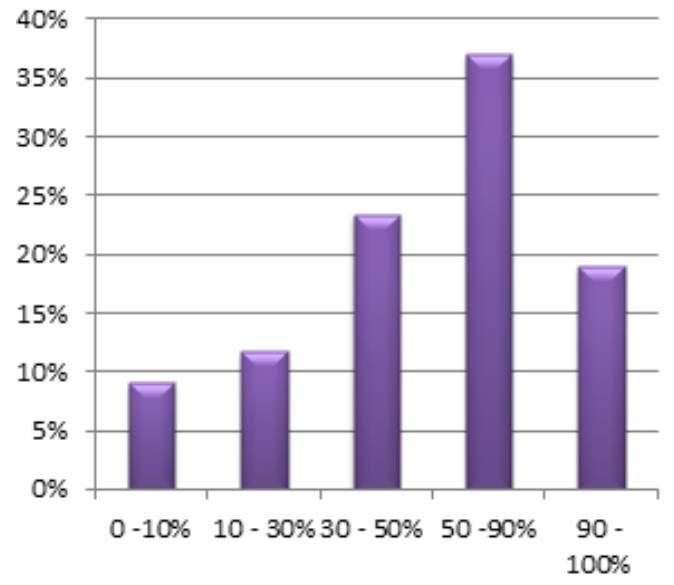

Fig. 6. Agile approaches increase customers satisfaction $(\mathrm{N}=103)$.

\subsection{Delivering software on time}

The result of this question in Fig. 7 indicates the available options such as SA = Strongly Agree, $\mathrm{A}=$ Agree, $\mathrm{SWA}=$ Somewhat Agree, $\mathrm{UnD}=$ Undecided, DA = Disagree and the responses based on their experiences. Those who strongly agreed said that they deliver software within shortest time period recoded $73.01 \%$, and those who somewhat agreed said that agile approaches increased delivery of software within shortest time period by $15.87 \%$ while those who agreed were $6.34 \%$ and the remaining available responses were less than $5 \%$.

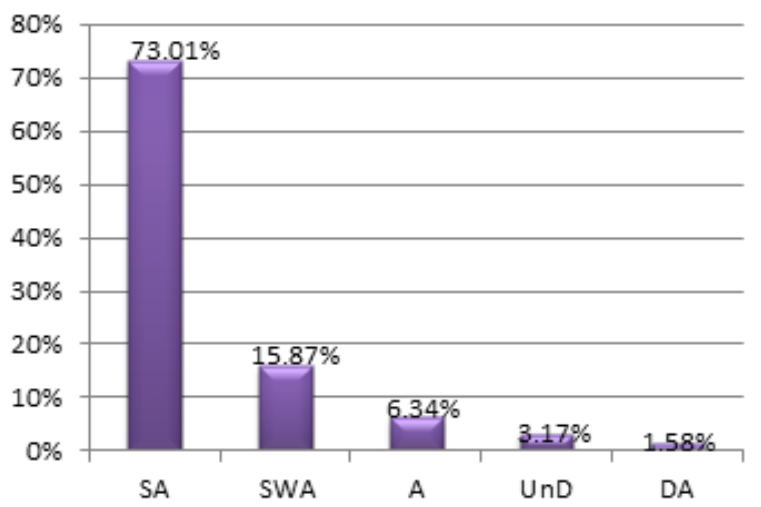

Fig. 7. Delivering software in time $(\mathrm{N}=103)$. 


\subsection{Ability to manage changes}

The result of this question in Fig. 8 indicates the available options such as SA = Strongly Agree, $\mathrm{A}=$ Agree, $\mathrm{SWA}=$ Somewhat Agree, $\mathrm{UnD}=$ Undecided, DA = Disagree and the responses based on their experiences. Those who strongly agreed recoded $42.85 \%$, and those who agreed said that agile approaches increased their ability to entertain customer requests or manage frequent requirement changes within shortest time period by $28.57 \%$ while those who somewhat agreed, undecided and disagreed were less than $10 \%$.

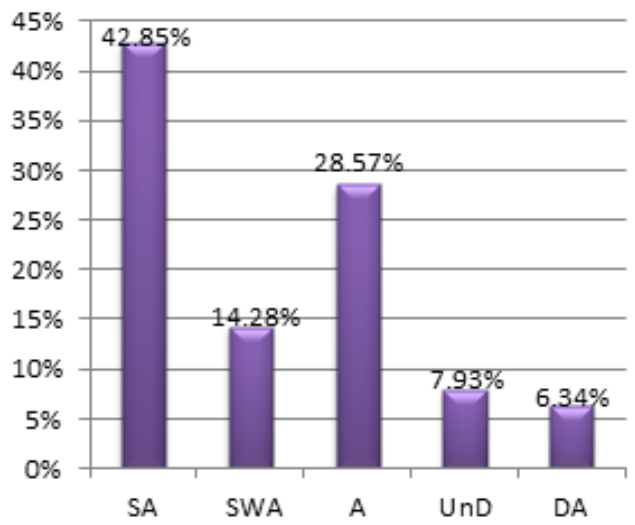

Fig. 8. Ability to manage changes $(\mathrm{N}=103)$.

From this analysis we can figure out that these factors have impacted on agile adoption as a result organisations will make great achievements interms of return of investment, reduce cost, increase efficiency and inprove customers satisfaction ingeneral.

\section{4 . Hypothesis Test Results}

In this section, we discuss the findings of the hypothesis tests based on correlations. We formed nine hypotheses. The entire nine hypotheses are tested using the bivariate correlation option in the SPSS package, where $P$ is the level of significance and $r$ is the correlation value of the sample. The resulting Pearson correlation formula is described below:

$$
r=\frac{n\left(\sum x y\right)-\left(\sum x\right)\left(\sum y\right)}{\sqrt{\left[n \sum x^{2}-\left(\sum x\right)^{2}\right]\left[n \sum y^{2}-\left(\sum y\right)^{2}\right]}}
$$

Where:

$\mathrm{N}=$ number of pairs of scores

$\sum x y=$ sum of the products of paired scores

$\sum \mathrm{x}=$ sum of $\mathrm{x}$ scores

$\sum \mathrm{y}=$ sum of $\mathrm{y}$ scores

$\sum \mathrm{x}^{2}=$ sum of squared $\mathrm{x}$ scores

$\sum \mathrm{y}^{2}=$ sum of squared y scores 
This equation is embedded in the SPSS Software. In the data view of SPSS, we selected the analyse function on the menu bar, select correlate, then Bivariate to select the number of variables and select the Pearson correlation among the three options that we had Pearson, Kendall's tau-b and the Spearman from there we computed the results. However, that produced a number for our two variables which lied between -1 and +1 inclusive. If the number was closer to negative it meant the relationship was strong negative relationship while if it was closer to +1 it meant strong positive relationship and if it was zero (0) it meant there was no relation between the two variables.

In fact, the nature of the data is what determines the type of correlation to select or choose. Moreover, our data is continuous and normal distributive no outliers, therefore Pearson correlation is the right one to use [9].

The input of the output is from the sample population of the survey data, that is sample of 46 out of our total dataset of respondents which is 103 and the result is computed using SPSS package, for calculating the nine hypothesis [21].

\subsection{Testing Hypothesis 1}

Ho: There is no relationship between senior management support and performance of IT-organizations using agile development methods. $\quad$ Ho $: Y=0 \quad$ Ha $: Y \neq 0$

A two tailed pearson correlation test was performed, and significant correlation was found between senior management support and performance of IT-organizations that used agile development methods, $\mathrm{r}(46)=0.127$, sig. $(2$-tailed $)=0.039, \mathrm{p}<0.05$. Where $\mathrm{P}$ is the level of significance and $r$ is the correlation value of the sample. As a result, we reject $\mathrm{H}_{\mathrm{o}}$ and accept Ha under the $95 \%$ confidence level. In other words, there is a relationship between senior management support and performance of IT-organizations that use agile development methods.

Table 1. Correlation result of MS and impact in term of Quality, Cost and Time

\begin{tabular}{|l|c|c|l|}
\hline & Pearson Correlation & Significance value & Significance \\
\hline Quality & 0.132 & 0.383 & Not significant \\
\hline Cost & 0.73 & 0.036 & Significant \\
\hline Time & 0.58 & 0.031 & Significant \\
\hline
\end{tabular}

The above Table 1, describes that the cost and time have a significant correlation with senior management support while quality does not have significant correlation.

\subsection{Testing Hypothesis 2}

Ho: There is no relationship between friendly-agile organization and performance of
$\begin{array}{ll}\text { IT-organizations using agile development methods. } & \text { Ho } Y=0 \text { Ha }: Y \neq 0\end{array}$

Two tailed pearson correlation test was performed, and a highly significant correlation was found between agile-friendly organization and performance of IT-organizations that use agile development methods., $r(46)=0.293$, sig. $(2$-tailed $)=0.048, p<0.05$. Where $\mathrm{P}$ is the level of significance and $r$ is the correlation value of the sample. As a result, we reject 
$\mathrm{H}_{\mathrm{o}}$ and accept Ha under the 95\% confidence level. Therefore, there is relationship between agile-friendly organization and performance of IT-organizations that use agile development methods.

Table 2. Correlation result of FAO and impact in term of Quality, Cost and Time

\begin{tabular}{|l|c|c|l|}
\hline & Pearson Correlation & Significance value & Significance \\
\hline Quality & 0.453 & 0.002 & Significance \\
\hline Cost & 0.217 & 0.148 & Not .significant \\
\hline Time & 0.869 & 0.000 & Significance \\
\hline
\end{tabular}

According to Table 2, it describes very clearly that the quality and time have a significant correlation with agile-friendly organizations while cost does not have significant correlation.

\subsection{Testing Hypothesis 3}

Ho: There is no relationship between Scope of customer requirements and performance of

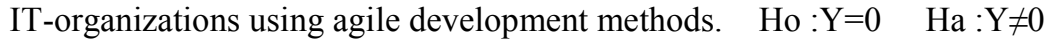

Two tailed pearson correlation test was performed, and a significant correlation was found between scope of customer requirements and performance of IT-organizations that use agile development methods, $\mathrm{r}(46)=0.156$, sig. $(2$-tailed $)=0.000, \mathrm{p}>0.05$. As a result, we reject $\mathrm{H}_{\mathrm{o}}$ and accept $\mathrm{Ha}$ under the $95 \%$ confidence level that indicates there is a relationship between Scope of customer requirements and performance of IT-organizations that use agile development methods.

Table 3. Correlation result of SCR and impact in term of Quality, Cost and Time.

\begin{tabular}{|l|c|c|l|}
\hline & Pearson Correlation & Significance value & Significance \\
\hline Quality & 0.358 & 0.014 & Significant \\
\hline Cost & 0.001 & 0.050 & Significant \\
\hline Time & 0.116 & 0.043 & Significant \\
\hline
\end{tabular}

According to Table 3, Quality and Cost have a significant correlation with Scope of customer requirements while Time does not have significant correlation.

\subsection{Testing Hypothesis 4}

Ho: There is no relationship between time to deliver software and performance of IT-organizations using agile development methods. Ho $: Y=0 \quad$ Ha $: Y \neq 0$

Two tailed pearson correlation test was performed, and a reasonable significant correlation was found between time to deliver software and performance of IT-organizations that use agile development methods, $r(46)=0.153$, sig. (2-tailed) $=0.031$, $\mathrm{p}<0.05$. Where $\mathrm{P}$ is the level of significance and $\mathrm{r}$ is the correlation value of the sample. As a result, we reject $\mathrm{H}_{\mathrm{o}}$ and accept $\mathrm{Ha}$ under the $95 \%$ level of confidence. 
Table 4. Correlation result of TDS and impact in term of Quality, Cost and Time

\begin{tabular}{|l|c|c|l|}
\hline & Pearson Correlation & Significance value & Significance \\
\hline Quality & 0.203 & 0.177 & Not significant \\
\hline Cost & 0.079 & 0.050 & Significant \\
\hline Time & 0.288 & 0.030 & Significant \\
\hline
\end{tabular}

According to Table 4, it describes vividly that the cost and time have a significant correlation with time to deliver software while quality does not have significant correlation.

\subsection{TestingHypothesis 5}

Ho: There is no relationship between strong customer involvement and performance of IT-organizations using agile development methods. Ho $: Y=0$ Ha $: Y \neq 0$

Two tailed pearson correlation test was performed, and we found no significant correlation between strong customer involvement and performance of IT-organizations that use agile development methods, $\mathrm{r}(46)=0.015$, sig. $(2$-tailed $)=0.092, \mathrm{p}<0.05$. Where $\mathrm{P}$ is the level of significance and $\mathrm{r}$ is the correlation value of the sample. As a result, we reject $\mathrm{H}_{\mathrm{a}}$ and accept $\mathrm{H}_{0}$.

Table 5. Correlation result of CI and impact in term of Quality, Cost and Time.

\begin{tabular}{|l|c|c|l|}
\hline & Pearson Correlation & Significance value & Significance \\
\hline Quality & 0.007 & 0.044 & Significant \\
\hline Cost & 0.352 & 0.016 & Significant \\
\hline Time & 0.115 & 0.447 & Not significant \\
\hline
\end{tabular}

According to Table 5 above, Quality and Cost have a significant correlation with strong customer involvement while Time does not have significant correlation.

\subsection{TestingHypothesis 6}

Ho: There is no relationship between a good delivery strategy and performance. of IT-organizations using agile development methods.

Ho $: Y=0$ Ha $: Y \neq 0$

Two tailed pearson correlation test was performed, and we found reasonable significant correlation between good delivery strategy and performance of IT-organizations that use agile development methods, $\mathrm{r}(46)=0.121$, sig. $(2$-tailed $)=0.042, \mathrm{p}<0.05$. Where $\mathrm{P}$ is the level of significance and $\mathrm{r}$ is the correlation value of the sample. Therefore, we reject $\mathrm{H}_{0}$ and accept Ha under the $95 \%$ confidence level.

Table 6. Correlation result of DS and impact in term of Quality, Cost and Time. 


\begin{tabular}{|l|c|c|l|}
\hline & Pearson Correlation & Significance value & Significance \\
\hline Quality & 0.281 & 0.029 & Significant \\
\hline Cost & 0.262 & 0.079 & Not significant \\
\hline Time & 0.013 & 0.030 & Significant \\
\hline
\end{tabular}

According to Table 6, time and quality have a significant correlation with delivery strategy while cost does not have significant correlation.

\subsection{TestingHypothesis 7}

Ho: There is no relationship between training of staff and performance of IT-organizations using other agile development method. Ho $: Y=0$ Ha $: Y \neq 0$

Two tailed pearson correlation test was performed, and we found reasonable significant correlation between training of staff and performance of IT-organizations that use other agile development method, $\mathrm{r}(46)=0.221$, sig. $(2$-tailed $)=0.028, \mathrm{p}<0.05$. Where $\mathrm{P}$ is the level of significance and $\mathrm{r}$ is the correlation value of the sample. Therefore, we reject $\mathrm{H}_{0}$ and accept Ha under the $95 \%$ confidence level.

Table 7. Correlation result of TOS and impact in term of Quality, Cost and Time

\begin{tabular}{|l|c|c|l|}
\hline & Pearson Correlation & Significance value & Significance \\
\hline Quality & 0.103 & 0.495 & Not Significant \\
\hline Cost & 0.126 & 0.404 & Not significant \\
\hline Time & 0.610 & 0.601 & Not Significant \\
\hline
\end{tabular}

According to Table 7, time and quality have a significant correlation with delivery strategy while cost does not have significant correlation.

\subsection{TestingHypothesis 8}

Ho: There is no relationship between language aspect (English) in creating agile awareness and performance of IT-organizations using other agile development method. $\quad$ Ho $: Y=0$ $\mathrm{Ha}: \mathrm{Y} \neq 0$

Two tailed pearson correlation test was performed, and we found significant correlation between language aspect (English) in creating agile awareness and performance of IT-organizations that use other agile development method, $\mathrm{r}(46)=0.081$, sig. (2-tailed) $=$ $0.042, \mathrm{p}<0.05$. Where $\mathrm{P}$ is the level of significance and $\mathrm{r}$ is the correlation value of the sample. Therefore, we reject $\mathrm{H}_{0}$ and accept Ha under the $95 \%$ confidence level.

Table 8. Correlation result of MS and impact in term of Quality, Cost and Time

\begin{tabular}{|l|c|c|l|}
\hline & Pearson Correlation & Significance value & Significance \\
\hline Quality & 0.331 & 0.025 & Significant \\
\hline Cost & 0.122 & 0.071 & Not significant \\
\hline Time & 0.013 & 0.020 & Significant \\
\hline
\end{tabular}

According to Table 8, time and quality have a significant correlation with delivery strategy while cost does not have significant correlation. 


\subsection{TestingHypothesis 9}

Ho: There is no relationship between agile project management process and performance of IT-organizations using other agile development method. Ho :Y=0 Ha $: Y \neq 0$

Two tailed pear son correlation test was performed, and we found significant correlation between agile-friendly team environment and performance of IT-organizations that use other agile development method, $r(46)=0.208$, sig. $(2$-tailed $)=0.001, p<0.05$. Where $\mathrm{P}$ is the level of significance and $\mathrm{r}$ is the correlation value of the sample. Therefore, we reject $\mathrm{H}_{0}$ and accept Ha under the $95 \%$ confidence level.

Table 9. Correlation result of PMP and impact in term of Quality, Cost and Time

\begin{tabular}{|l|c|c|l|}
\hline & Pearson Correlation & Significance value & Significance \\
\hline Quality & 0.471 & 0.039 & Significant \\
\hline Cost & 0.340 & 0.021 & significant \\
\hline Time & 0.013 & 0.060 & Not Significant \\
\hline
\end{tabular}

According to Table 9, quality and cost have a significant correlation with delivery strategy while time does not have significant correlation.

\subsection{Summary of Hypothesis Test Results as Guideline}

The Table 10 below summarizes all results of the correlation and gives clear picture of the significant factors in the hypothesis test results that can serves as guideline to companies and organizations.

Table 10. Summarizing hypothesis test results

\begin{tabular}{|l|l|}
\hline Factors & Correlation results \\
\hline Very strong management support & Significant \\
\hline Friendly-agile organization and team environment & Significant \\
\hline Team that is skilled & Significant \\
\hline Strong customers involvement & Significant \\
\hline Responsive project management process & Significant \\
\hline Efficient delivery techniques & Significant \\
\hline Training of staff & Significant \\
\hline Language aspect English & Significant \\
\hline Agile project management process & Significant \\
\hline
\end{tabular}

These success factors correlate closely with the work of [21]. Their study found the following factors to be most critical to the success of an agile systems development project: The team environment, capability of the project team, level of customer involvement and the project management process.

In addition to that, the following success factors also correlated: an organizational environment for agile, very strong management support, the appropriate management of 
the agile process with a frequent delivery of usable software meeting frequently changing requirements, language aspect english and cooperative organizational culture instead of hierarchical were all success factors which correlated with the performance of IT-organizations using agile development methods.

\subsection{Agile Experts and Practitioners Recommendations}

In the Table 11 below, we briefly describe some of the recommendations by experts and agile practitioners pertaining to the three most important things that make agile software development methods successful and also the three most important problems that they encounter with applying agile software development methods in their organizations. The identity of the experts is kept as confidential, hence we use Expert 1, Expert 2,........... and Expert 18.

Table 11. Agile Experts and Practitioners Recommendations

\begin{tabular}{|c|c|c|}
\hline & $\begin{array}{l}\text { Three Most Important Things for } \\
\text { Successful Agile Software } \\
\text { Development }\end{array}$ & $\begin{array}{l}\text { Three Most Important Problems } \\
\text { Encountered with Agile Software } \\
\text { Development Methods. }\end{array}$ \\
\hline Expert 1 & $\begin{array}{l}\text { 1.Executive buy-in. } \\
\text { 2.Good product owners. } \\
\text { 3.Retrospectives. }\end{array}$ & $\begin{array}{l}\text { 1.Culture and mentality changes. } \\
\text { 2.No interest in championing improvement. } \\
\text { 3.Bad scrum masters that are bad servant } \\
\text { leaders. }\end{array}$ \\
\hline Expert 2 & $\begin{array}{l}\text { 1.Executive buy in. } \\
\text { 2.Excellent PO- Requirement are firm. } \\
\text { 3.Understanding of agile method for } \\
\text { involving parties. }\end{array}$ & $\begin{array}{l}\text { 1. Executive or senior management not } \\
\text { buy-in or understanding. } \\
\text { 2. Lack feature driven by the set teams. } \\
\text { 3. Blur requirement or objective. }\end{array}$ \\
\hline Expert 3 & $\begin{array}{l}\text { 1. Freedom to change } \\
\text { 2.Business requirement clearly } \\
\text { defined. } \\
\text { 3.Good collaboration between owner } \\
\text { and project team. }\end{array}$ & $\begin{array}{l}\text { 1.No co-operation from high level } \\
\text { management. } \\
\text { 2.Unclear business requirement. } \\
\text { 3.Timeline. }\end{array}$ \\
\hline Expert 4 & $\begin{array}{l}\text { 1. Faster delivery. } \\
\text { 2.Customer involvement in testing } \\
\text { beta builds. } \\
\text { 3.Faster in identifying important } \\
\text { features. }\end{array}$ & $\begin{array}{l}\text { 1.Deciding the most important feature. } \\
\text { 2.How to breakdown features in to smaller } \\
\text { units. } \\
\text { 3.Coders capability to complete codes or } \\
\text { task within a sprint. }\end{array}$ \\
\hline Expert 5 & $\begin{array}{l}\text { 1.Increamentalism } \\
\text { 2.Resources skill. } \\
\text { 3.Managementand methodology used. }\end{array}$ & $\begin{array}{l}\text { 1.Cross skilling. } \\
\text { 2.Bad scrum master. } \\
\text { 3.Retrospective. }\end{array}$ \\
\hline Expert 6 & $\begin{array}{l}\text { 1.Transparency and honest. } \\
\text { 2.Synchronised approach. } \\
\text { 3.Mailing changes to product based on } \\
\text { customer feedback so that final } \\
\text { product is closer to what is planned or } \\
\text { required. }\end{array}$ & $\begin{array}{l}\text { 1.Organization culture and mentality to } \\
\text { changes. } \\
\text { 2. No interest in championing } \\
\text { improvement. } \\
\text { 3. Unclear business requirement. }\end{array}$ \\
\hline
\end{tabular}




\begin{tabular}{|c|c|c|}
\hline Expert 7 & $\begin{array}{l}\text { 1. Effective Team Collaboration } \\
\text { 2. Accurate effort estimation } \\
\text { 3.Due diligence on each role }\end{array}$ & $\begin{array}{l}\text { 1.Resistance to change. } \\
\text { 2.Like of passion to improve. } \\
\text { 3.Mindset fixed. }\end{array}$ \\
\hline Expert 8 & $\begin{array}{l}\text { 1. Visibility } \\
\text { 2. Reduce risk } \\
\text { 3.Attention to quality }\end{array}$ & $\begin{array}{l}\text { 1.How to decide the most important } \\
\text { feature. } \\
\text { 2.How to breakdown features in to smaller } \\
\text { units. } \\
\text { 3.Coders capability to complete codes or } \\
\text { task within a sprint. }\end{array}$ \\
\hline Expert 9 & $\begin{array}{l}\text { 1. Communication among the } \\
\text { developers and business user. } \\
\text { 2. Always adopt the changes. } \\
\text { 3. Working software. }\end{array}$ & $\begin{array}{l}\text { 1.Culture of the company } \\
\text { 2.People with agile knowledge } \\
\text { 3.SuiTable. tool for different projects. }\end{array}$ \\
\hline Expert 10 & $\begin{array}{l}\text { 1.Transferency } \\
\text { 2. Cross-functional teams } \\
\text { 3.Highest ROI requirements } \\
\text { prioritized }\end{array}$ & $\begin{array}{l}\text { 1.Transferency } \\
\text { 2.Management interaction } \\
\text { 3.Scrumbutt }\end{array}$ \\
\hline Expert 11 & $\begin{array}{l}\text { 1.Client involvement or mandate. } \\
\text { 2.Team skill } \\
\text { 3.Team mindset }\end{array}$ & $\begin{array}{l}\text { 1.Client involvement or mandate. } \\
\text { 2.Team skill } \\
\text { 3.Team mindset }\end{array}$ \\
\hline Expert 12 & $\begin{array}{l}\text { 1.People (right people) } \\
\text { 2.Management involvement and } \\
\text { support } \\
\text { 3.Automation }\end{array}$ & $\begin{array}{l}\text { 1.Self organizing to a new team. } \\
\text { 2.Commitment from people. } \\
\text { 3.Last minute change adopt. }\end{array}$ \\
\hline Expert 13 & $\begin{array}{l}\text { 1.Software developers ability and skill } \\
\text { set. } \\
\text { 2. Communication with stakeholder } \\
\text { and follow up on matters. } \\
\text { 3. Interpretation of product owner and } \\
\text { tester developer on business. }\end{array}$ & $\begin{array}{l}\text { 1.Product owner understanding } \\
\text { 2. Require high involvement from user. } \\
\text { 3. Lack of skill set from software } \\
\text { developer. He to know more than just } \\
\text { technical skills. }\end{array}$ \\
\hline Expert 14 & $\begin{array}{l}\text { 1.Shorter feedback loop } \\
\text { 2. Preparedness for ability to change. } \\
\text { 3. Team collaboration. }\end{array}$ & $\begin{array}{l}\text { 1.Management mindset, lack of support. } \\
\text { 2.Fake agile. } \\
\text { 3.Ecosystem. }\end{array}$ \\
\hline Expert 15 & $\begin{array}{l}\text { 1. Customer involvement. } \\
\text { 2. Team maturity. } \\
\text { 3. Good scrum master. }\end{array}$ & $\begin{array}{l}\text { 1. Management overhead. } \\
\text { 2. Knowledge of skill of team member. } \\
\text { 3. Customer expectation. }\end{array}$ \\
\hline Expert 16 & $\begin{array}{l}\text { 1. Adoption to change. } \\
\text { 2. Self organize. } \\
\text { 3. Quality froud. }\end{array}$ & $\begin{array}{l}\text { 1. Resistance to change. } \\
\text { 2. Passion to improve. } \\
\text { 3.Mindset fixed. }\end{array}$ \\
\hline Expert 17 & $\begin{array}{l}\text { 1.The organization and team have to } \\
\text { understand agile, believe in scrum. } \\
\text { 2.Proper planning and understand } \\
\text { requirement (what customer want). } \\
\text { 3.Proper implementation. }\end{array}$ & $\begin{array}{l}\text { 1.Poor planning, communication, vague } \\
\text { requirements. } \\
\text { 2.Poor understanding of scrum or agile } \\
\text { 3.Ad-hoc tasks. }\end{array}$ \\
\hline Expert 18 & $\begin{array}{l}\text { 1.Delivers, better quality. } \\
\text { 2. Proper communication among the }\end{array}$ & $\begin{array}{l}\text { 1. Mad push behind popular agile models. } \\
\text { 2. Require high involvement from }\end{array}$ \\
\hline
\end{tabular}


developers and business user.

3. Exhibiting good agile behaviors. stakeholders.

3.Improper co-operation from top management to developers.

\subsection{Summary of our survey}

Based on our survey analysis in a nutshell, we state that the popular agile methodology adopted by majority of IT organizations is Scrum. We noted that generally the highest percentage of respondents (50\% to $90 \%)$ said agile approaches have increased managers', developers' and customers' satisfaction significantly that indicates IT organizations should embrace agile methods more.

In addition, it is important to note that the largest team size with agile approaches is 6 to 10 members for better performance. Moreover, agile based projects that practice co-located agile team are more successful and has improved organizational performance.

Furthermore, it was noted that the return on investment (ROI) has significantly increased by using agile approaches by $50 \%$ to $90 \%$ of respondents. Based on agile experts' experiences they strongly agreed that they wre able to manage changes and deliver software within shortest time period.

By and large, some of the barriers were identified as to further adoption of agile in organizations such as the decision-making is greatly influenced by organizational culture, mainly by executives within the organization. Moreover, lack of knowledge of agile methods as well as lack of knowledge of benefits were major constraints in the adoption. Nevertheless, it was also noted that most of the respondents, who have not yet started agile in their organizations, showed interest and willingness to adopt agile software development within the next 3 months.

\section{Conclusion}

This study was conducted to know the impact of agile adoption on the performance of IT organization of the world. In order to conduct this research we set out to design a survey to explore the barriers and success factors that have an impact on the performance of IT-organizations in some countries of the world. The data was collected from Linkedin.

The main finding of this research is the relationship with the success factors identified and their impact in performance of IT-organizations. The organizations that want to adopt agile methodologies and the project managers who wish to try them as the project management methodologies should take into consideration these identified problems and success factors, specifically, very strong support management, friendly-agile organization and team environment, team that is skilled, strong customer involvement, responsive project management process and to have an efficient delivery techniques to make the project more successful. Some professionals from at least two organizations commented that they did not use Scrum or Kanban directly but they used mix of agile concepts. 
Our profound gratitude goes to the Ministry of Higher Education (MOHE) Malaysia for funding this research project under Vot: 4F315.

\section{References}

[1] Bulgaria, S.S, The State of Agile Software Development Bulgaria 2013. Presentation Slide, 2013. Article (CrossRef Link).

[2] Gandomani, T.J., et al., "Towards comprehensive and disciplined change management strategy in agile transformation process," Research Journal of Applied Sciences, Engineering and Technology, vol. 6(13), pp. 2345-2351, 2013. Article (CrossRef Link).

[3] Thakur, S. and A. Kaur, "Role of Agile Methodology in Software Development," 2013. Article (CrossRef Link).

[4] Sletholt, M.T et al., "A literature review of agile practices and their effects in scientific software development," in Proc. of the 4th International Workshop on Software Engineering for Computational Science and Engineering, 2011: ACM. Article (CrossRef Link).

[5] Bustard, D., G. Wilkie, and D. Greer, "The Maturation of Agile Software Development Principles and Practice: Observations on Successive Industrial Studies in 2010 and 2012," in Engineering of Computer Based Systems (ECBS), in Proc. of 2013 20th IEEE International Conference and Workshops on the 2013: IEEE. Article (CrossRef Link).

[6] Kumar, A. and B. Goel, "Factors Influencing Agile Practices: A Survey," International Journal of Engineering Research and Applications, 2012. Article (CrossRef Link).

[7] Ghani, I. and I. Yasin, "SOFTWARE SECURITY ENGINEERING IN EXTREME PROGRAMMING METHODOLOGY: A SYSTEMATIC LITERATURE," 2013. Article (CrossRef Link).

[8] Ingason, H.T., E. Gestsson, and H.I. Jonasson, "The Project Kanban Wall: Combining Kanban and Scrum for Coordinating Software Projects," 2013. Article (CrossRef Link).

[9] Kniberg, H. and M. Skarin, "Kanban and Scrum-making the most of bothm," 2010: Lulu. com. Article (CrossRef Link).

[10] Bresciani, P., et al., "Tropos: An agent-oriented software development methodology." Autonomous Agents and Multi-Agent Systems, vol. 8(3): p. 203-236, 2004. Article (CrossRef Link).

[11] Ghani, I., N. Izzaty, and A. Firdaus, "ROLE-BASED EXTREME PROGRAMMING (XP) FOR SECURE SOFTWARE DEVELOPMENT". Article (CrossRef Link).

[12] Ghani, I., N. Izzaty, and A. Firdaus, "ROLE-BASED EXTREME PROGRAMMING (XP) FOR SECURE SOFTWARE DEVELOPMENT," 2013. Article (CrossRef Link).

[13] Boehm, B. "A view of 20th and 21st century software engineering," in Proc. of the 28th international conference on Software engineering, 2006: ACM. Article (CrossRef Link).

[14] Kongyai, B. and E. Edi, "Adaptation of Agile Practices: A Systematic Review and Survey," 2011. Article (CrossRef Link).

[15] Firdaus, A., I. Ghani, and S.R. Jeong, "Secure Feature Driven Development (SFDD) Model for Secure Software Development," Procedia-Social and Behavioral Sciences, vol. 129: p. 546-553, 2014. Article (CrossRef Link).

[16] CORONA, E. and F.E. PANI, "A Review of Lean-Kanban Approaches in the Software Development," WSEAS Transactions on Information Science \& Applications, vol. 10(1), 2013. Article (CrossRef Link).

[17] Chow, T. and D.-B. Cao, "A survey study of critical success factors in agile software projects" 
Journal of Systems and Software, vol. 81(6): p. 961-971, 2008. Article (CrossRef Link).

[18] Cockburn, A. and J. Highsmith, "Agile software development, the people factor," Computer, vol. 34(11): p. 131-133, 2001. Article (CrossRef Link).

[19] Vijayasarathy, L. and D. Turk, "Agile Software Development: A survey of early adopters," Journal of Information Technology Management, vol. 19(2): p. 1-8, 2008. Article (CrossRef Link).

[20] Gandomani, T.J., Zulzalil, H., Ghani, A. A. A., \& Sultan, A. B. M. , "Effective factors in agile transformation process from change management perspective," arXiv preprint arXiv:1302.2747., 2013. Article (CrossRef Link).

[21] Asnawi, A.L., A.M. Gravell, and G.B. Wills, "An empirical study: Understanding factors and barriers for implementing agile methods in Malaysia," in 5th International Doctoral Symposium on Empirical Software Engineering. 2010. Article (CrossRef Link).

[22] Rico, D.F., et al., "A model for measuring agile methods and website quality," TickIT International, vol. 9(3): p. 3-15, 2007. Article (CrossRef Link).

[23] Livermore, J.A., "Factors that Significantly Impact the Implementation of an Agile Software Development Methodology," Journal of Software (1796217X), 3(4), 2008. Article (CrossRef Link).

[24] Nasehi, A., "A Quantitative Study on Critical Success Factors in Agile Software Development Projects; Case Study IT Company," 2013. Article (CrossRef Link).

[25] Khalid, M., A. Khan, and M. Naeem, "An Assessment of Extreme Programming Based Requirement Engineering Process," International Journal of Modern Education \& Computer Science, vol. 5(2), 2013. Article (CrossRef Link).

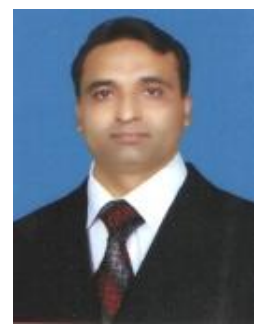

Imran Ghani is a Senior Lecturer at Faculty of Computing, Universiti Teknologi Malaysia (UTM), Johor Campus. He received his Master of Information Technology Degree from UAAR (Pakistan), M.Sc. Computer Science from UTM (Malaysia) and Ph.D. from Kookmin University (South Korea). His research focus includes agile software development methods and practices, semantics techniques, secure software development life cycle, web services, software testing, enterprise architecture and software architecture.

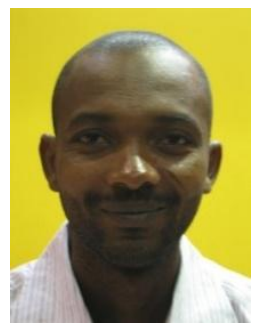

Mannir Bello is working at Isa Kaita College of Education Dutsinma, Katsina State, Nigeria. He received his M.Sc. Computer Science degree from UTM (Malaysia). His research interests include agile software development methods and practices, survey analysis, and software process improvement. 